\title{
Serious intraoperative problems - a five-year review of 83,844 anesthetics
}

\author{
[Problèmes peropératoires graves - une revue de 83844 anesthésies sur cinq ans]
}

Sigurd Fasting MD, Sven E. Gisvold MD PhD

Purpose: The low incidence of mortality and major morbidity in anesthesia makes it difficult to study the pattern of potential accidents and to develop preventive strategies. Anesthetic 'near-misses', however, occur more frequently. Using data from a simple routine-based system of problem reporting, we have analyzed the pattern and causes of serious non-fatal problems, in order to improve preventive strategies.

Methods: We prospectively recorded anesthesia-related information from all anesthetics for five years. The data included intraoperative problems, which were graded into four levels, according to severity. We analyzed only the serious nonfatal problems, which were sorted according to clinical presentation, and also according to which factor was most important in the development of the problem. We assessed any untoward consequences for the patient, and whether the problems could have been prevented.

Results: Serious problems were recorded in 315 cases out of 83,844 (0.4\%). Anesthesia was considered the major contributing factor in I I I cases. Difficult intubation, difficult emergence from general anesthesia, allergic reactions, arrhythmia and hypotension were the dominating problems. Twenty-six anesthesia related problems resulted in changes in level of postoperative care, and one patient later died in the intensive care unit after anaphylactic shock. Eighty-two problems could have been prevented by simple strategies.

Conclusion: Analysis of serious nonfatal problems during anesthesia may contribute to improved preventive strategies. Data from a routine-based system are suitable for this type of analysis. Intubation, emergence, arrhythmia, hypotension and anaphylaxis cause most serious problems, and should be the object of preventive strategies.

Objectif : La faible incidence de mortalité et de morbidité importante en anesthésie complique l'étude des types d'accidents potentiels et la mise au point de stratégies préventives. Les quasi accidents anesthésiques, par contre, surviennent plus fréquemment. En utilisant les données d'un simple système de notification de cours normal, nous avons analysé le type et les causes de problèmes graves, non mortels, dans le but d'améliorer les stratégies préventives.

Méthode : Nous avons enregistré prospectivement les informations reliées à toutes les anesthésies réalisées pendant cinq ans. Les données comprenaient les problèmes peropératoires que nous avons classés selon quatre niveaux de sévérité. Nous avons analysé les problèmes graves, non mortels, qui ont été retenus d'après la présentation clinique et aussi en fonction du facteur le plus important de l'évolution du problème. Nous avons évalué toutes les conséquences négatives pour le patient et la possibilité de prévention de ces problèmes.

Résultats : Des problèmes graves ont été notés dans 315 cas sur 83844 (0,4\%). L'anesthésie a été considérée comme le principal facteur dans $1 /$ I cas. L'intubation difficile, le retour à la conscience difficile après l'anesthésie générale, les réactions allergiques, l'arythmie et l'hypotension ont dominé le tableau. Vingt-six problèmes reliés à l'anesthésie ont entrainé la modification des soins postopératoires et un patient est décédé à l'unité des soins intensifs d'un choc anaphylactique. Quatre-vingt-deux problèmes auraient pu être évités par de simples interventions.

Conclusion : L'analyse de problèmes graves, mais non mortels, survenus pendant l'anesthésie peut contribuer à l'amélioration de stratégies préventives. Les données obtenus d'un système régulier de notification sont pertinentes à ce genre d'analyse. L'intubation, le retour à la conscience, l'arythmie, l'hypotension et l'anaphylaxie causent les problèmes les plus graves et devraient être prévenus.

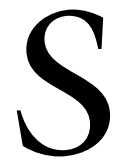

YSTEMS for reporting 'near-misses' have been used successfully to improve safety in aviation. Similar systems have also been recommended as a basis for risk reduction in medicine. ${ }^{1-3}$

Anesthetic complications, such as mortality and major morbidity, do not occur spontaneously but are

From the Department of Anesthesia and Intensive Care, St. Olav's Hospital, University Hospital of Trondheim, Trondheim, Norway. Address correspondence to: Dr. Sigurd Fasting, Department of Anesthesia and Intensive Care, St. Olav's Hospital, University Hospital of Trondheim, N-7006 Trondheim, Norway. Phone: +47-73868108; Fax: +47-73868117; E-mail: sigurd.fasting@medisin.ntnu.no

The study is supported with grants from the Norwegian Medical Research Council.

Accepted for publication January 8, 2002.

Revision accepted March 15, 2002. 
the outcome of an evolutionary process. Through multiple interactions, a simple incident evolves to a serious one that may further evolve to an accident. ${ }^{4}$ Because of recovery processes such as error detection and treatment, minor incidents are more common than serious incidents, which in turn occur more frequently than accidents. The rarity of mortality and major anesthetic morbidity makes it difficult to study the etiology of adverse outcomes and to develop preventive strategies. ${ }^{1,5-7}$ However, the greater frequency of incidents or 'near misses' affords opportunities for accident prevention, as well demonstrated in aviation, nuclear power and other high-risk industries. ${ }^{1-3}$

We report our analysis of serious problems during anesthesia, almost all of which would be classified as critical incidents, in that most did not progress to a serious outcome. The data are derived from a simple routine based system of problem reporting, recorded in a clinical database. ${ }^{8}$ Our aim was to analyze the pattern and causes of serious problems, and then to use this information to improve preventive strategies.

\section{Methods}

Our department uses a system for routine data recording during all anesthetics. ${ }^{8}$ One part of the standard anesthetic record is devoted to specific data fields. It is mandatory to complete these by the end of the case. The fields on all the charts are checked for completeness and accuracy by a consultant anesthesiologist before data are entered into a database. A copy of the anesthetic chart is stored.

One of the data fields, 'intraoperative problems' (Appendix), includes a list of 22 common anesthesiological problems, as well as a field for severity (grade 1-4). The anesthesiologist writes a short description of any problem occurring during the anesthetic, and marks the 'problem checkbox' on the chart accordingly. If the case was 'uneventful', this also must be indicated in a checkbox. Other data fields on the chart relate to the patient, the operation, type of anesthetic, and timing of events.

An 'intraoperative problem' is defined as 'an event that requires one or more measures either to prevent further complications, or to treat a situation that is currently or potentially serious, and which does not routinely occur during the conduct of anesthesia.' The problems are graded according to severity, using a scale from one to four. 'Grade l' is a trivial problem, easily dealt with and not affecting the patient's condition. 'Grade 2' represents moderate difficulty, with some effect on the patient, but of a low severity. 'Grade 3' is a serious situation which is either very difficult to manage, or which causes a serious deterioration in the patient's state, and which may or may not have postoperative consequences. 'Grade 4' problems imply a fatal outcome during anesthesia and surgery.

All cases of general anesthesia, regional anesthesia, and sedation for surgical procedures from the years 1996-2000 were selected from the departmental database, and included in the study cardiac surgery was excluded $(n=3,405)$. Cases with recorded problem situations of 'grade 3' and 'grade 4' severity were identified and analyzed more closely. The copies of the corresponding anesthetic charts were retrieved from departmental archives. The authors performed the analysis of the cases, using predefined criteria for severity or clinical judgement, based on the patient's medical history, the documentation on the anesthetic chart, and the information in the database.

Firstly, the problems were sorted according to their clinical presentation: hypotension, intubation problems, arrhythmia, allergy, difficult emergence and other. Secondly, we assigned the problems to one of three categories, according to which 'major factor' was considered the most important in the progression of the problem. These categories were 'Anesthesia,' 'The patient's medical condition,' and 'Surgery.' Thirdly, we then determined any 'contributing factors,' using the same three categories. Fourthly, we further analyzed the problems where 'Anesthesia' was the major factor, or a contributing factor in cases where the patient's medical condition was the most important, to see if there were any untoward consequences, such as postponement of surgery, or the need for an increased level of postoperative care. Lastly, we evaluated if these problems could have been prevented - and which preventive strategies could have been used.

A chi square test was performed to compare groups, and $P<0.05$ was considered statistically significant.

\section{Results}

During the five-year study period, 83,844 cases met the inclusion criteria. Grade 1-4 problems were recorded in 13,191 cases $(15.7 \%)$. There were 321 cases of 'grade 3 ' severity. Eight were excluded; three had been entered incorrectly, and five were reclassified as 'grade 2.' Two cases were added to the 'grade 3 ' group from the 'grade 4' group; one was entered incorrectly, and one coded wrongly. The remaining 315 cases represented $0.4 \%$ of all anesthetics. There were significantly more grade 3 problems with general anesthesia than with regional anesthesia or sedation (Table I).

Table II shows that anesthesia was considered the major contributing factor in 111 cases, surgery in 23, and the patient's medical condition in 181. Also 
shown is the clinical presentation of the problems, with hypotension, intubation problems, arrhythmia, difficult emergence from general anesthesia, and allergy in descending order of frequency. Considering only problems in which 'anesthesia' was the major factor, the same groups dominate, but in a different order: intubation problems, difficult emergence, allergy, arrhythmia, and hypotension.

Where anesthesia was the major causative factor, 82 problems were considered preventable. Where the patient's condition was the major factor, anesthesia was judged a contributing factor in 78 cases, 22 of which were considered preventable.

\section{Hypotension}

Serious hypotension occurred in 124 patients (Table II). Anesthesia was the major factor in only 13 cases, in contrast to surgery ( $n=18$; bleeding) and the patient's medical condition ( $n=93$; trauma, ruptured aortic aneurysm, septic shock, heart failure). Anesthesia was a contributing factor in an additional 27 cases, where the major factor was the patient's condition. Details of the 40 cases where anesthesia was a major or contributing factor are presented in Table III.

Three patients in whom anesthesia was considered the major factor needed unplanned admission to the intensive care unit (ICU); in two of these, the problems were considered preventable. One patient had severe hypotension and myocardial infarction after induction of general anesthesia, secondary to failed spinal blockade. Five of the patients in whom anesthesia was considered a contributory factor required an unplanned admission to the ICU; all problems were considered preventable.

Possible preventive measures included improved preoperative evaluation and stabilization of seriously ill patients, and better choice of the induction doses.

\section{Problems with intubation}

Eighty-two serious intubation problems were recorded in 40,423 general anesthetics with tracheal intubation $(0.2 \%)$. Anesthesia was considered the major factor in 25 cases, and a contributing factor in 41 cases, when the main contribution was the patient's medical (or anatomical) condition (Table II).

Details of the 66 intubation problems related to anesthesia are shown in Table IV. Twenty-nine were considered preventable. Failed recognition of anatomical stigmas for difficult intubation, and choice of inappropriate primary intubation technique in patients where intubation was known or suspected to be difficult, were the most common causes.

With unexpected intubation difficulties, more
TABLE I Demographic data and occurence of problems according to type of anesthesia

\begin{tabular}{llll}
\hline & $\begin{array}{l}\text { General } \\
\text { anesthetics }\end{array}$ & $\begin{array}{l}\text { Regional } \\
\text { anesthetics }\end{array}$ & Sedation \\
\hline All cases $(n)$ & 59,185 & 20,564 & 4,095 \\
Cases with problems & 9,451 & 3,541 & 199 \\
(grade $1-4 ; n)$ & $(16.0 \%)^{*}$ & $(17.2 \%)$ & $(4.9 \%)^{*} \dagger$ \\
Cases with serious & $270(0.5 \%)$ & $39(0.2 \%) \dagger$ & $6(0.1 \%) \dagger$ \\
problems (grade 3; $n)$ & & & \\
General surgery (\%) & 27 & 23 & 60 \\
Orthopedic surgery (\%) & 23 & 64 & 8 \\
Gynecological/Obstetrical & 30 & 10 & 3 \\
surgery (\%) & & & \\
Neurosurgery (\%) & 8 & - & - \\
Other (\%) & 12 & 3 & 29 \\
Age (yr) \pm SD & $35.7 \pm 23.5$ & $58.3 \pm 20.155 .3 \pm 21.2$ \\
\hline
\end{tabular}

${ }^{*} P<0.01$ compared to regional anesthetics; $\dagger P<0.01$ compared to general anesthetics. $\mathrm{SD}=$ standard deviation.

TABLE II Serious problems occuring during anesthesia analyzed for major causative factor

\begin{tabular}{lllll}
\hline Clinical problem & \multicolumn{4}{c}{ Major factor } \\
& Anesthesia & Surgery & $\begin{array}{l}\text { Medical } \\
\text { condition }\end{array}$ & Total \\
\hline Hypotension & 13 & 18 & $93(27)$ & 124 \\
Intubation difficulties & 25 & - & $57(41)$ & 82 \\
Arrhythmia & 14 & 1 & $12(3)$ & 27 \\
Difficult emergence & 23 & 2 & $2(2)$ & 27 \\
Allergy & 14 & - & - & 14 \\
Oxygenation problems & - & - & 8 & 8 \\
Aspiration & 4 & - & $1(1)$ & 5 \\
Laryngeal spasm & 4 & - & - & 4 \\
Drug error & 4 & - & - & 4 \\
Respiratory arrest & 3 & - & - & 3 \\
Myocardial ischemia & - & - & $3(1)$ & 3 \\
Bronchospasm & 1 & - & $2(2)$ & 3 \\
Technical problem & 2 & - & - & 2 \\
Other & 4 & 2 & $3(1)$ & 9 \\
Total number & 111 & 23 & $181(78)$ & 315 \\
\hline
\end{tabular}

Numbers in parenthesis are cases where anesthesia was considered a contributory factor.

patients were seriously affected by hypoxemia or airway problems during the intubation procedure than when the problems were anticipated $(13 / 42$ vs $0 / 24, P<$ $0.01)$. There was no difference in difficulty with mask ventilation $(10 / 42$ vs $4 / 24)$.

There was no difference in the need to modify postoperative management between those with anticipated problems $(6 / 24)$ compared to those with unexpected problems $(17 / 42)$. No patient suffered any lasting morbidity.

Possible preventive measures included better routines for preoperatively predicting difficult intubation, 
and algorithms for choosing the optimal primary intubation technique in cases with anticipated difficulties.

\section{Arrbythmias}

There were 27 serious arrhythmias. Anesthesia was the major factor in 14 , surgery in one, and the patient's medical condition in 12. Three of the latter had anesthesia as a contributory factor (Table II). Details of the anesthesia related arrhythmias are presented in Table V. The largest group comprised extreme bradycardia or asystole $(n=14)$. Eleven occurred during spinal anesthesia, four developing more than $60 \mathrm{~min}$ after onset of blockade. Five patients received chest compressions in addition to medication. Five patients with arrhythmia needed ICU admission; mainly because of their poor medical condition. Five of the problems were considered preventable (Table V).

Possible preventive measures in this group include improving the evaluation of patients before choosing the anesthetic technique, and better routines for monitoring during all phases of anesthesia care.

\section{Problems during emergence from general anesthesia}

We recorded 27 serious problems during emergence; only two were unrelated to anesthesia; they suffered postoperative bleeding during emergence, one posttonsillectomy, and one postcraniotomy. All the anesthesia-related cases had undergone tracheal intubation, and suffered severe airway or oxygenation problems during emergence. Eight of the 23 patients where anesthesia was the major factor, and the two patients where the major factor was surgery, needed unplanned admission to the ICU. No serious problems were recorded during emergence from mask anesthesia or laryngeal mask anesthesia.

All anesthesia related problems were considered preventable. Fourteen were related to misjudgment of residual drug effect, usually opioids or muscle relaxants. In three cases, extubation should not have been attempted because of poor general condition or lung function. In five cases, the patient had severe laryngoor bronchospasm after extubation, and one patient aspirated. The most important possible preventive measures were a more critical application of extubation criteria, including possible residual effect of drugs, and consideration of delayed extubation in the ICU.

\section{Allergy problems}

Fourteen patients had serious allergic reactions. Thirteen had severe anaphylactoid or anaphylactic reactions during approximately 40,000 cases of general anesthetics with neuromuscular blocking drugs $(1: 3,000)$. Four had to be admitted to the ICU. One patient developed anaphylactic shock with treatmentresistant cardiac arrest, and later died in the ICU. Three reactions were associated with the use of succinylcholine, and ten with non-depolarizing drugs.

One patient, undergoing gastroscopy with sedation, developed angioedema in the face and throat, requiring ICU admission. The patient was on angiotensin converting enzyme-inhibitors, which are known to be associated with angioedema. ${ }^{9}$ Two patients had a history of drug allergy, although not to any anesthetic drugs. None of the allergy problems were considered preventable; prevention is difficult, but early diagnosis and prompt and aggressive treatment may prevent morbidity.

\section{Other problems}

Pulmonary aspiration occurred in five patients who were having general anesthesia. Four had serious underlying medical conditions predisposing to gastric retention, but rapid sequence induction was not performed. Two were admitted to ICU after aspiration. All cases of aspiration were considered preventable, and anesthesia was considered a major factor.

Serious laryngospasm occurred in four patients, two of whom were children. All had airway and oxygenation problems. All were considered preventable with better anesthetic techniques, but the problems did not affect postoperative care.

Three patients received hypoxic gas mixtures when the intention was to give $100 \%$ oxygen, and in one patient a syringe containing succinylcholine was mistaken for saline and used to flush an $i v$ line while the patient was still awake. All these problems were preventable, and did not influence the patient's postoperative course.

Other less common problems are presented in Table II. All incidents in which anesthesia was a major factor, were considered preventable, other problems were not. Only one patient, who suffered a pneumothorax, needed admission to ICU.

\section{Problems of grade 4 - intraoperative death}

Forty-two patients died intraoperatively, all were ASA IV or V, except three with uncontrollable surgical bleeding. The most common diagnoses were ruptured aortic aneurism $(n=21)$, multitrauma $(n=8)$, and septic shock $(n=5)$. There were no anesthesia related deaths.

\section{Clinical consequences}

Twenty-seven percent $(85 / 315)$ of all 'grade 3' problems resulted in a change in the patient's expected postoperative course. Sixty-one had an unplanned 
TABLE III Hypotension

\begin{tabular}{|c|c|c|}
\hline \multirow{3}{*}{$\begin{array}{l}\text { Anesthesia major factor: } \\
13 \text { cases }\end{array}$} & Preventable: & Three general anesthesia cases: \\
\hline & 9 cases & $\begin{array}{l}\text { - Underestimated preoperative hypovolemia } \\
\text { and/or excessive induction doses } \\
\text { Six regional anesthesia cases: } \\
\text { - Five spinals - inadequate fluid resuscitation, or drug overdose in cases } \\
\text { with underestimated preoperative hypovolemia } \\
\text { - One local - attempted nerve block in the neck, resulting in total spinal } \\
\text { anesthesia }\end{array}$ \\
\hline & $\begin{array}{l}\text { Not preventable: } \\
4 \text { cases }\end{array}$ & $\begin{array}{l}\text { Four regional anesthesia cases: } \\
\text { - Four spinals - delayed onset of hypotension and bradycardia after } \\
\text { institution of block, no special risk factors }\end{array}$ \\
\hline \multirow[t]{2}{*}{$\begin{array}{l}\text { Anesthesia contributing } \\
\text { factor: } \\
27 \text { cases }\end{array}$} & $\begin{array}{l}\text { Preventable: } \\
14 \text { cases }\end{array}$ & $\begin{array}{l}\text { Nine general anesthesia cases with serious } \\
\text { medical conditions: } \\
\text { - Eight - excessive anesthesia induction doses } \\
\text { - One - pressor drugs given } s c \text {, when iv was intended } \\
\text { Five spinal/epidural anesthesia cases with serious medical conditions: } \\
\text { - Four - relative overdose of local anesthetic } \\
\text { - One - sudden change in patient position }\end{array}$ \\
\hline & $\begin{array}{l}\text { Not preventable: } \\
13 \text { cases }\end{array}$ & $\begin{array}{l}\text { Ten general anesthesia cases with serious medical conditions: } \\
\text { - Severe hypotension in spite of careful anesthetic care } \\
\text { Three spinal anesthesia cases with serious medical conditions: } \\
\text { - Delayed onset of hypotension and bradycardia after institution } \\
\text { of blockade }\end{array}$ \\
\hline
\end{tabular}

TABLE IV Intubation problems

\begin{tabular}{|c|c|c|}
\hline $\begin{array}{l}\text { Anesthesia major factor: } \\
25 \text { cases }\end{array}$ & $\begin{array}{l}\text { Preventable: } \\
25 \text { cases }\end{array}$ & $\begin{array}{l}\text { - Sixteen - anatomical stigma suggestive of } \\
\text { difficult intubation, but these were not recognized before induction of } \\
\text { anesthesia. } \\
\text { - Six - intubation difficulties were expected, but problems still occurred, } \\
\text { and could have been prevented by choice of primary intubation } \\
\text { technique, better preoperative evaluation, or alternative anesthetic } \\
\text { technique. } \\
\text { - Two - difficult to reintubate after accidental extubation. } \\
\text { - One - in an infant where problems were caused by poor } \\
\text { intubation technique. }\end{array}$ \\
\hline $\begin{array}{l}\text { Anesthesia contributing } \\
\text { factor: } 41 \text { cases }\end{array}$ & $\begin{array}{l}\text { Preventable: } \\
4 \text { cases }\end{array}$ & $\begin{array}{l}\text { - Expected difficulties - problems could } \\
\text { have been prevented by other primary intubation technique, better } \\
\text { preoperative evaluation, or other anesthetic technique. }\end{array}$ \\
\hline & $\begin{array}{l}\text { Not preventable: } \\
37 \text { cases }\end{array}$ & $\begin{array}{l}\text { - Fourteen - expected difficulties, but serious problems occurred in } \\
\text { spite of optimal preparation and technique } \\
\text { - Twenty-three - no apparent stigma for difficult intubation judged by } \\
\text { evaluation of mouth opening, neck movement, and general appearance. }\end{array}$ \\
\hline
\end{tabular}

ICU admission, three underwent tracheotomy, and in 21 the operation was postponed because of intubation difficulties. One patient later died in the ICU after an anaphylactic reaction.

Among the problems where anesthesia was considered the major factor, 23\% (26/111) resulted in a change of plans. Eighteen patients had to be admitted to ICU, one had a tracheotomy, and in seven, surgery was postponed because of intubation difficulties.

Among patients with preventable anesthesia problems $24 \%(20 / 82)$ had a change in postoperative course. Thirteen had to be admitted to ICU, one had a tracheotomy, and in six cases, surgery was postponed because of intubation difficulties.

\section{Discussion}

These results, compiled from a routine based system for problem reporting in anesthesia, use an approach similar to 'near miss' reporting as employed in aviation and other high-risk industries. ${ }^{1-3}$ Serious, but not fatal, problems occurred in $0.4 \%$ of patients. Anesthesia was the major contributory factor in onethird of these, chiefly intubation problems, difficult emergence, allergy, arrhythmia, and hypotension. 
TABLE V Arrhythmia problems

\begin{tabular}{|c|c|c|}
\hline \multirow{3}{*}{$\begin{array}{l}\text { Anesthesia main factor: } \\
14 \text { cases }\end{array}$} & Preventable: & - One - inadvertent $i v$ injection of local \\
\hline & 4 cases & $\begin{array}{l}\text { - Onesthetic - ventricular tachycardia } \\
\text { plexus block. } \\
\text { - One - spinal - known tedency to vasovagal reactions, no } \\
\text { anticholinergic given } \\
\text { - One - general anesthesia - extreme bradycardia after } 2 \mathrm{mg} \text { of } \\
\text { physostigmine. }\end{array}$ \\
\hline & $\begin{array}{l}\text { Not preventable: } \\
10 \text { cases }\end{array}$ & $\begin{array}{l}\text { - Ten - spinal anesthesia with extreme bradycardia or asystole. Onset } \\
\text { occurred a variable time after institution of block, no cases of excessive } \\
\text { doses, no special risk factors. }\end{array}$ \\
\hline \multirow{4}{*}{$\begin{array}{l}\text { Anesthesia contributing } \\
\text { factor: } 3 \text { cases }\end{array}$} & Preventable: & - One - poor medical condition - extreme \\
\hline & 1 case & $\begin{array}{l}\text { bradycardia or asystole during transport to the recovery unit after general } \\
\text { anesthesia. No monitoring during transport. }\end{array}$ \\
\hline & Not preventable: & Two patients in poor medical condition: \\
\hline & 2 cases & $\begin{array}{l}\text { - One - sedation - extreme bradycardia/asystole - no other risk factors. } \\
\text { - One - supraventricular tachycardia during attempts at spinal anesthesia. }\end{array}$ \\
\hline
\end{tabular}

Two-thirds of these problems were considered preventable by simple strategies.

\section{Methodology}

Anesthetic mortality and serious morbidity are becoming exceedingly rare, and therefore their analysis is of limited value for quality improvement efforts. ${ }^{1,5-7}$ This is also the case in our study, in which all the intraoperative deaths were caused by life-threatening medical conditions or surgical factors. Study of the 'near miss' - the serious nonfatal anesthetic problem - is therefore a more valuable starting point for preventive strategies, $5,6,10,11$ a philosophy used in aviation and other complex non-medical industries for years. ${ }^{1,3}$

On the other hand, it has been argued that intraoperative incidents are 'surrogate outcomes' for 'real' postoperative morbidity. ${ }^{12}$ Our study focused on serious nonfatal intraoperative problems, which have an undeniable potential for serious morbidity and mortality. Twenty-three percent of these problems affected the patient's postoperative course, either as an unplanned admission to ICU, or postponement of surgery.

Since all patients receiving an anesthetic were included in the study, and critical incidents were recorded systematically for all anesthetics, important events were unlikely to be missed. This contrasts to studies where information is collected from selected samples of patients. However, underreporting may still occur, possible causes being the added workload of completing forms, the belief that reporting is of limited value, and fear of consequences of reporting. ${ }^{13-16}$ We believe that the reporting compliance in our study was good, since our system is designed to add minimal workload. All recording is done directly on the anesthetic chart, and no additional paperwork is needed. The data is used actively in our department, for morbidity meetings and quality improvement projects. Further, we have created a nonpunitive reporting culture, where it is 'safe' to admit and report problems. Problems are met with an attitude of 'learn and prevent' rather than 'blame and hide, ${ }^{17}$ and thus we believe that the reported incidence is representative for our practice.

\section{Frequency and pattern of serious problems}

Intubation, difficult emergence, arrhythmia, anaphylaxis and hypotension were the commonest serious problems. Four studies, all representing mandatory reporting, are partially comparable to ours. ${ }^{10,18-20}$ These report both the occurrence and severity of incidents, but all have evaluated incidents in the perioperative period, i.e., in the operating room and the recovery room together.

Cooper and coworkers reported incidents in the operating room or the recovery room as 'recovery room impact events' (RRIE). ${ }^{10}$ A RRIE was 'an event that needed intervention, was pertinent to recovery room care, and did or could cause mortality, or at least moderate morbidity.' A RRIE occurred in the operating room in $13.8 \%$ of the anesthetics, but the severity of these events was not stated. The four most frequent intraoperative problems in this study were hypotension, arrhythmia, hypertension and difficult intubation.

Three studies have been published from a large German Quality Assurance project. ${ }^{18-20}$ Sixty-three types of incidents were defined, and five levels of severity according to their impact on postoperative care. Serious problems (severity class $4-5$ ) occurred in $1.2 \%$ in 18,350 
cases, ${ }^{18} 0.9 \%$ in 26,907 cases, ${ }^{19}$ and $1.0 \%$ in 96,000 cases. $^{20}$ The frequency of all problems was $23.2 \%, 27.9 \%$ and $22 \%$ respectively. ${ }^{18-20}$ The most common serious problems were respiratory, arrhythmia, and hypotension.

Again, comparison with our study, is difficult, as these studies also included recovery room events. We did not use the 'recovery room impact' as a criterion for severity, as it may not always be adequate. For example most airway problems are treated without sequel, but still have the potential for catastrophic outcome. ${ }^{21}$ It is important to evaluate the potential for disaster as well as the actual morbidity.

\section{Hypotension}

Hypotension is the most common serious problem in our study, as elsewhere, ${ }^{10,18-20}$ but its exact definition is difficult. We defined it as a reduction to $<70 \%$ of baseline for more than five minutes, or any reduction to $<50 \%$.

Serious hypotension was related principally to serious medical conditions or surgical bleeding, rather than anesthesia. The most important preventive measures were thus better preoperative evaluation, stabilization, and better adjustment of induction drug dosage.

Fourteen cases of serious hypotension were caused by circulatory collapse during central neuraxial blockade. Seven of these were caused by inadequate correction of hypovolemia before blockade, a recognized risk factor. ${ }^{22}$

\section{Problems with intubation}

Airway problems are an important cause of death and serious morbidity, ${ }^{23-25}$ our incidence was $0.2 \%$. In a study by Rose and Cohen, $0.4 \%$ of cases required more than three attempts at laryngoscopy, and 0.3\% could not be intubated by standard laryngoscopic techniques. ${ }^{26}$ Again, the frequency of problems will vary according to the definition used..$^{27}$

Unexpected intubation difficulties are more likely to produce hypoxemia and, therefore, probably have a greater accident potential than expected difficulties. Different methods for preoperative airway evaluation have been tested with different predictive values. ${ }^{26,28-30}$ We evaluated mouth opening and neck movement, but have not included strict assessment of thyromental distance or Mallampati score in our routine evaluation. Nearly half of our patients with unexpected intubation problems had anatomical stigma predicting intubation difficulties when re-evaluated after the incident. Better routines for preoperative evaluation may help reduce the risk. ${ }^{28,31}$

Fortunately, no intubation problem resulted in major morbidity or mortality. We discontinued attempts at intubation in one-third of the cases, and two patients had a tracheotomy. Early discontinuation of intubation attempts is advised, ${ }^{31}$ and may have prevented serious morbidity in our study.

\section{Difficult emergence from general anesthesia}

Difficult emergence from general anesthesia was associated with serious problems in our study, but is seldom mentioned explicitly elsewhere. The main problems were related to airway and hypoventilation, and the 'emergence problems' may have been categorized as airway problems in other studies.

The causes were either misjudgment of residual drug effect or of the patient's respiratory status before extubation. We do not routinely monitor neuromuscular blockade, and there is pressure to extubate in the operating room, rather than in the postoperative care unit, where capacity is limited. Possibly, delayed extubation should be considered more often; our routines need to be re-evaluated.

\section{Arrbythmia}

Bradycardia and asystole were the most common serious arrhythmias. Their low frequency probably reflects prompt diagnosis and treatment of bradycardia and hypotension during central neuraxial blockade. Prompt intervention is necessary to avoid life-threatening circulatory collapse. 22,32

One ventricular arrhythmia was caused by accidental $i v$ injection of local anesthetic, and is a reminder that full resuscitation facilities are needed when performing regional anesthesia.

\section{Allergy-anaphylaxis}

The frequency of serious allergic reactions was $1: 6,000$ in our study, while in the German studies the frequency ranged from 1:4,500 to 1:6,400. ${ }^{18-20}$ In a French study by Laxenaire and coworkers the frequency of anaphylactic and anaphylactoid reactions during anesthesia was $1: 4,850 .{ }^{33}$ In the studies by Laxenaire and coworkers, anaphylactic shock had a $1 \%$ rate of mortality or severe neurological sequelae. ${ }^{33,34}$ The only patient to die in our study was a man, ASA class II, in whom hypotension and tachycardia dominated the symptoms and delayed the diagnosis of anaphylaxis. Circulatory collapse is the sole predominant symptom in about $10 \%$ of anaphylactic reactions associated with anesthesia, ${ }^{34}$ and it is important to bear this in mind when a patient develops severe hypotension after drug injection.

\section{Other problems}

We had no cases of 'classic' aspiration of gastric contents, i.e., patients with a suspected full stomach or 
peritonitis who aspirated during induction. We follow the Norwegian 'National Fasting Guidelines', ${ }^{35}$ which recommend preoperative gastric emptying only before induction of general anesthesia where ileus is suspected. Earlier, we had shown these routines to be safe. ${ }^{36}$ However, it is important to evaluate the risk for pulmonary aspiration also in patients outside the 'classic full stomach' group, as gastric retention can be secondary to other serious conditions. The frequency of serious aspiration is very low in our study and similar to that in our previous study. ${ }^{36}$

\section{Quality issues}

To compare problem frequencies with other studies is difficult, because of differences in definitions and recording systems. ${ }^{10,19,20,37}$ Cohen and coworkers found that, even with the same recording system, comparisons between hospitals were difficult. ${ }^{6}$ However, for departmental use, the frequency and pattern of problems may be useful indicators of quality. A routine based system will also track changes in problem patterns and occurrence, allowing continuous adjustment of preventive and educational efforts.

Nevertheless, the serious problems reported within one institution also represent a 'lesson for all'. The patterns and possible preventive strategies are transferable to other institutions, and may be suitable for accumulation in a central database, as in the Australian AIMS project ${ }^{38}$ and in parallel to systems for reporting 'near misses' in aviation. ${ }^{1-3}$

\section{Conclusion}

The greater frequency of near-misses in anesthesia, as opposed to accidents, may be analyzed quantitatively and areas and strategies for prevention can be identified. Our simple routine based reporting system is similar to systems used in high-risk industries. ${ }^{1,2}$ Information on serious non-fatal problems tells us where we have the greatest potential for disaster, and suggests where corrective actions should be taken. Intubation, emergence, arrhythmia, hypotension, and anaphylaxis constitute the greatest potential for disaster. Our reporting system will allow us to monitor the effect of corrective strategies, any changes in the pattern of problems and, ultimately, to improve patient care.

\section{References}

1 Barach P, Small SD. Reporting and preventing medical mishaps: lessons from non-medical near miss reporting systems. BMJ 2000; 320: 759-63.

2 Billings CE. Some hopes and concerns regarding medical event-reporting systems. Lessons from the NASA Aviation Safety Reporting System (Editorial). Arch
Pathol Lab Med 1998; 122: 214-5.

3 Helmreich RL. On error management: lessons from aviation. BMJ 2000; 320: 781-5.

4 Gaba DM, Maxwell M, DeAnda A. Anesthetic mishaps: breaking the chain of accident evolution.

Anesthesiology 1987; 66: 670-6.

5 Cooper JB. How to measure what happens. Can J Anaesth 1991; 38: 1032-3.

6 Cohen MM, Duncan PG, Pope WDB, et al. The Canadian four-centre study of anaesthetic outcomes: II. Can outcomes be used to assess the quality of anaesthesia care? Can J Anaesth 1992; 39: 430-9.

7 Lee A, Lum ME. Measuring anaesthetic outcomes. Anaesth Intensive Care 1996; 24: 685-93.

8 Fasting S, Gisvold SE. Data recording of problems during anaesthesia: presentation of a well-functioning and simple system. Acta Anaesthesiol Scand 1996; 40: 1173-83.

9 Vleeming W, van Amsterdam JGC, Stricker BHC, de Wildt DJ. ACE inhibitor-induced angioedema. Incidence, prevention and management. Drug Saf 1998; 18: 171-88.

10 Cooper JB, Cullen DJ, Nemeskal R, et al. Effects of information feedback and pulse oximetry on the incidence of anesthesia complications. Anesthesiology 1987; 67: 686-94.

11 Spencer FC. Human error in hospitals and industrial accidents: current concepts. J Am Coll Surg 2000; 191: 410-8.

12 Orkin FK, Cohen MM, Duncan PG. The quest for meaningful outcomes. Anesthesiology 1993; 78: $417-22$.

13 Sanborn KV, Castro J, Kuroda M, Thys DM. Detection of intraoperative incidents by electronic scanning of computerized anesthesia records. Comparison with voluntary reporting. Anesthesiology 1996; 85: 977-87.

14 Cooper JB. Is voluntary reporting of critical events effective for quality assurance? Anesthesiology 1996; 85: 961-4.

15 Cullen DJ, Bates DW, Small SD, Cooper JB, Nemeskal $A R$, Leape $L L$. The incident reporting system does not detect adverse drug events: a problem for quality improvement. Jt Comm J Qual Improv 1995; 21: 541-8.

16 Jayasuriya JP, Anandaciva S. Compliance with an incident report scheme in anaesthesia. Anaesthesia 1995; 50: 846-9.

17 Cohen MR. Why error reporting systems should be voluntary. BMJ 2000; 320: 728-9.

18 Schwilk B, Muche R, Bothner U, Goertz A, Friesdorf W, Georgieff $M$. Quality control in anesthesiology. Results of a prospective study following the recommendations of the German Society of Anesthesiology and Intensive 
Care (German). Anaesthesist 1995; 44: 242-9.

19 Schwilk B, Muche R, Treiber H, Brinkmann A, Georgieff $M$, Bothner $U$. A cross-validated multifactorial index of perioperative risks in adults undergoing anaesthesia for non-cardiac surgery. Analysis of perioperative events in 26907 anaesthetic procedures. J Clin Monit Comput 1998; 14: 283-94.

20 Bothner U, Georgieff M, Schwilk B. Building a largescale perioperative anaesthesia outcome-tracking database: methodology, implementation, and experiences from one provider within the German quality project. Br J Anaesth 2000; 85: 271-80.

21 Sigurdsson GH, McAteer E. Morbidity and mortality associated with anaesthesia. Acta Anaesthesiol Scand 1996; 40: 1057-63.

22 Stienstra $R$. Mechanisms behind and treatment of sudden, unexpected circulatory collapse during central neuraxis blockade. Acta Anaesthesiol Scand 2000; 44: 965-71.

23 Runciman WB. Risk assessment in the formulation of anaesthesia safety standards. Eur J Anaesthesiol Suppl 1993; 10(Suppl. 7): 26-32.

24 Tiret L, Desmonts JM, Hatton F, Vourc'h G. Complications associated with anaesthesia - a prospective survey in France. Can Anaesth Soc J 1986; 33: 336-44.

25 Caplan RA, Posner KL, Ward RJ, Cheney FW. Adverse respiratory events in anesthesia: a closed claims analysis. Anesthesiology 1990; 72: 828-33.

26 Rose DK, Cohen MM. The airway: problems and predictions in 18,500 patients. Can J Anaesth 1994; 41: 372-83.

27 Rose DK, Cohen MM. The incidence of air-way problems depends on the definition used. Can J Anaesth 1996; 43: 30-4.

28 Randell T. Prediction of difficult intubation. Acta Anaesthesiol Scand 1996; 40: 1016-23.

29 El-Ganzouri AR, McCarthy RJ, Tuman KJ, Tanck EN, Ivankovich $A D$. Preoperative airway assessment: predictive value of a multivariate risk index. Anesth Analg 1996; 82: 1197-204.

30 Arné J, Descoins P, Fusciardi J, et al. Preoperative assessment for difficult intubation in general and ENT surgery: predictive value of a clinical multivariate risk index. Br J Anaesth 1998; 80: 140-6.

31 Crosby ET, Cooper RM, Douglas MJ, et al. The unanticipated difficult airway with recommendations for management. Can J Anaesth 1998; 45: 757-76.

32 Lovstad RZ, Granhus G, Hetland S. Bradycardia and asystolic cardiac arrest during spinal anaesthesia: a report of five cases. Acta Anaesthesiol Scand 2000; 44: 48-52.

33 Laxenaire $M C$ et le Groupe d'etudes des réactions anaphylactoïdes peranesthésiques. Épidémiologie des réac- tions anaphylactoïdes peranesthésiques. Quatrième enquête multicentrique (juillet 1994-décembre 1996). Ann Fr Anesth Reanim 1999; 18: 796-809.

34 Laxenaire MC, Mertes PM, and Groupe d'Etudes des Réactions Anaphylactoïdes Peranesthésiques. Anaphylaxis during anaesthesia. Results of a two-year survey in France. Br J Anaesth 2001; 87: 549-58.

35 Fasting S, Søreide E, Raeder JC. Changing preoperative fasting policies. Impact of a national consensus. Acta Anaesthesiol Scand 1998; 42: 1188-91.

36 Mellin Olsen J, Fasting S, Gisvold SE. Routine preoperative gastric emptying is seldom indicated. A study of 85 594 anaesthetics with special focus on aspiration pneumonia. Acta Anaesthesiol Scand 1996; 40: 1184-8.

37 Cohen MM, Duncan PG, Pope WDB, Wolkenstein C. A survey of 112,000 anaesthetics at one teaching hospital (1975-83). Can Anaesth Soc J 1986; 33: 22-31.

38 Webb RK, Currie M, Morgan CA, et al. The Australian Incident Monitoring Study: an analysis of 2000 incident reports. Anaesth Intensive Care 1993; 21: 520-8.

\section{APPENDIX}

Check list as printed on the anesthetic chart. If a problem occurs, the nature of the problem and its severity are indicated, as here an emergence problem of severity grade 3 . In addition, a short description of the problem is noted on the anesthetic chart.

\section{Uneventful}

Laryngeal spasm

Bronchospasm

Aspiration

Hypertension $>30 \%$

Hypotension $>30 \%$

Arrhythmia / ECG change

Intubation difficulties

Perforation of the dura

Convulsions

Tooth injury

Allergic reaction

Hypothermia $<35.5^{\circ} \mathrm{C}$

Hyperthermia $>39.0^{\circ} \mathrm{C}$

Bleeding $>20 \%$

Difficult emergence

Inadequate anesthesia/analgesia

Equipment/Technical problem

Cardiac arrest / CPR

Oxygenation problems / Hypoxaemia

Hypercapnia

Drug error / Syringe swap

Other

3 Severity of problem 